\title{
In-Situ Catalytic Upgrading of Tar and coke during Biomass /Coal Co-Pyrolysis
}

AUTHOR NAMES

Zhirong Yang ${ }^{\dagger, \grave{+}}$

Jing Zhang ${ }^{\dagger, *}$

Jiejie Huang

Gang Qian ${ }^{\dagger}$

Xuezhi Duan ${ }^{\dagger}$

Xinggui Zhou

AUTHOR ADDRESS

$†$ State Key Laboratory of Chemical Engineering, East China University of Science and Technology, Shanghai, 200237, China

State Key Laboratory of Coal Conversion, Institute of Coal Chemistry, Chinese Academy of Sciences, Taiyuan, Shanxi 030001, China

*Corresponding author. E-mail: jingzhang8507@ecust.edu.cn 
Table S1. Ash composition (\%) in biomass and coal sample

\begin{tabular}{ccccccccccc}
\hline Sample & $\mathrm{SiO}_{2}$ & $\mathrm{Al}_{2} \mathrm{O}_{3}$ & $\mathrm{Fe}_{2} \mathrm{O}_{3}$ & $\mathrm{CaO}$ & $\mathrm{MgO}$ & $\mathrm{TiO}_{2}$ & $\mathrm{SO}_{3}$ & $\mathrm{~K}_{2} \mathrm{O}$ & $\mathrm{Na}_{2} \mathrm{O}$ & $\mathrm{P}_{2} \mathrm{O}_{5}$ \\
\hline Bio & 47.72 & 4.79 & 5.33 & 7.73 & - & - & 1.82 & 14.93 & - & 3.72 \\
$\mathrm{GC}$ & 28.85 & 20.29 & 11.18 & 15.61 & 3.87 & 0.77 & 14.46 & 0.82 & 0.39 & 0.33 \\
$\mathrm{FC}$ & 43.26 & 38.26 & 13.28 & 0.58 & 0.17 & 0.99 & 0.36 & 0.43 & 0.14 & 0.08 \\
\hline
\end{tabular}

Biomass according to GB/T30725-2014, GC and FC according to GB/T1574-2007.

Table S2. Coordinates of Cracking points (A, B, C, D) on the periphery of coke

\begin{tabular}{lllll}
\hline \multirow{2}{*}{ Sample } & \multicolumn{5}{c}{ Position $(\mathrm{cm})$} \\
\cline { 2 - 5 } & $\mathrm{A}(\mathrm{x}, \mathrm{y}, \mathrm{z})$ & \multicolumn{1}{c}{$\mathrm{B}(\mathrm{x}, \mathrm{y}, \mathrm{z})$} & $\mathrm{C}(\mathrm{x}, \mathrm{y}, \mathrm{z})$ & $\mathrm{D}(\mathrm{x}, \mathrm{y}, \mathrm{z})$ \\
\hline \multirow{3}{*}{ Bio $20 \%$} & $(3.5,0,13.5)$ & $(-3.5,0,13.5)$ & $(0,3.5,13.5)$ & \\
& $(3.5,0,8.5)$ & $(-3.5,0,8.5)$ & $(0,3.5,10.5)$ & \\
& $(3.5,0,1)$ & $(-3.5,0,2.5)$ & $(0,3.5,6.5)$ & $(0,-3.5,6.5)$ \\
\multirow{3}{*}{ Bio 30\% } & $(3.5,0,13.5)$ & $(-3.5,0,13.5)$ & $(0,3.5,13.5)$ & \\
& $(3.5,0,11)$ & $(-3.5,0,11.5)$ & $(0,3.5,11.5)$ & \\
& $(3.5,0,8.5)$ & $(-3.5,0,7.5)$ & $(0,3.5,9.5)$ & $(0,-3.5,8.5)$ \\
& $(3.5,0,0)$ & & & $(0,-3.5,7)$ \\
Bio 40\% & $(3.5,0,13.5)$ & $(-3.5,0,13.5)$ & $(0,3.5,13.5)$ & \\
& $(3.5,0,10.5)$ & $(-3.5,0,11)$ & $(0,3.5,9)$ & \\
& $(3.5,0,7)$ & $(-3.5,0,9)$ & $(0,3.5,0)$ & \\
\hline
\end{tabular}


Table S3. Product distributions of GC-detectables from biomass pyrolysis by Py-GC-MS at $500{ }^{\circ} \mathrm{C}$

\begin{tabular}{cccc}
\hline Compounds & \multicolumn{3}{c}{ Content of relative peak areas (\%) } \\
\cline { 2 - 4 } & Bio & Bio-Ca & Bio-Ca $@ \mathrm{Cu}$ \\
\hline Acids & 10.84 & 7.36 & 3.62 \\
Ketones & 4.47 & 3.79 & 0.49 \\
Aldehydes & 2.40 & 1.91 & 0.97 \\
Amines & 3.15 & 2.62 & 0.37 \\
Furfurals & 4.31 & 2.47 & 1.61 \\
Furfuryl alcohols & 1.33 & 1.23 & 0.37 \\
Alkanes & 1.48 & 1.66 & 2.11 \\
Naphthalenes (NAPs) & 3.50 & 0.97 & 0.46 \\
Anthracenes (ANTs) & 1.89 & 2.17 & 2.96 \\
Indenes & 1.64 & 1.23 & 0.61 \\
Fluorenes & 4.82 & 3.86 & 2.44 \\
Cycloalkanes & 4.10 & 4.54 & 2.32 \\
Benzenes & 3.04 & 1.66 & 2.04 \\
Biphenyls & 4.11 & 3.07 & 0.41 \\
Quinolines & 0.68 & 0.48 & 1.03 \\
Carbazoles & 2.78 & 2.12 & 1.48 \\
Piperidines & 1.25 & 1.23 & 1.60 \\
Benzofurans, 2,3-dihydro- & 7.90 & 17.71 & 31.95 \\
Phenol and cresol & 1.73 & 3.29 & 1.14 \\
Hydroquinones & 2.49 & 2.71 & 2.60 \\
Methoxyphenols & 5.85 & 9.34 & 14.22 \\
Tert-butyl phenols & 23.54 & 23.01 & 22.63 \\
Total & 97.30 & 98.43 & 97.43 \\
\hline
\end{tabular}


Table S4. Detection of some key structures in aromatic compounds during biomass pyrolysis with $\mathrm{Ca} @ \mathrm{Cu}$ catalysis in Py-GC-MS (from Figure S3)

\begin{tabular}{|c|c|c|}
\hline Structure containing aromatic rings & No catalysis & $\mathrm{Ca} @ \mathrm{Cu}$ catalysis \\
\hline & less & no detection \\
\hline & less & no detection \\
\hline & moderate & less \\
\hline & no detection & less \\
\hline & less & more \\
\hline & less & more \\
\hline & no detection & less \\
\hline
\end{tabular}

Discussion for Table S4: There was a significant reduction in contents of light aromatics containing alkyl-side chain under catalysis of $\mathrm{Ca} @ \mathrm{Cu}$, but the contents of light aromatics containing methoxy/hydroxyl-side chain was increased, it indicates that light aromatics containing alkyl-side chains participated in the condensation reaction under catalysis, and selective cleavage of oxygen bridge bond on aromatic side-chain resulted in the generation of more oxygen-containing aromatic structures that inhibited their condensation with aromatic structure of macromolecules. Besides, more o-dimethoxyphenols were transferred to the benzofurans under catalysis followed the possible pathway below:

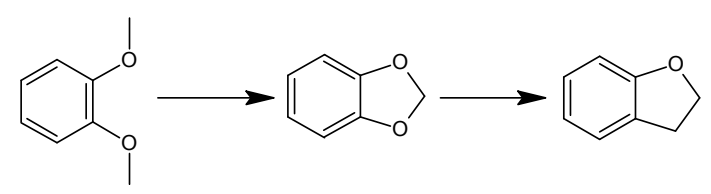



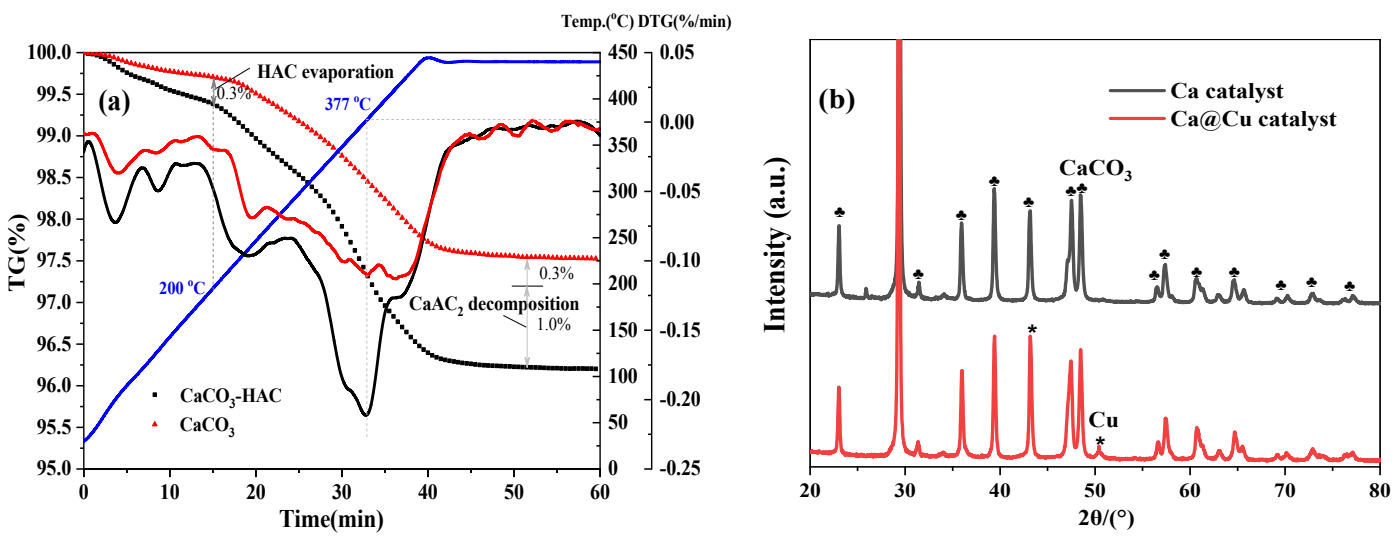

Figure S1. (a) Thermo-decomposition of $\mathrm{CaCO}_{3}-\mathrm{CaAC}_{2}$ by TG and (b) XRD patterns of $\mathrm{Ca}$ and $\mathrm{Ca} @ \mathrm{Cu}$ catalysts

Discussion for Figure S1: According to the TG results, 1.0\% weight loss was attributed to the $\mathrm{CaAC}_{2}$ decomposition, which was deducted that $1.32 \%$ of $\mathrm{CaCO}_{3}$ reacts with $\mathrm{HAC}$. The particle size of purchased calcium carbonate is $<30 \mu \mathrm{m}$, therefore, it is estimated that the thickness of $\mathrm{CaCO}_{3}$ involved in the reaction is $<0.12 \mu \mathrm{m}$. XRD patterns indicate that copper form existed in the $\mathrm{Ca} @ \mathrm{Cu}$ catalyst has the metallic copper $\left(\mathrm{Cu}^{0}\right)$ after copper nitrate being mixed and calcined, which may be caused by the reduction of CO released from calcium acetate calcined. 

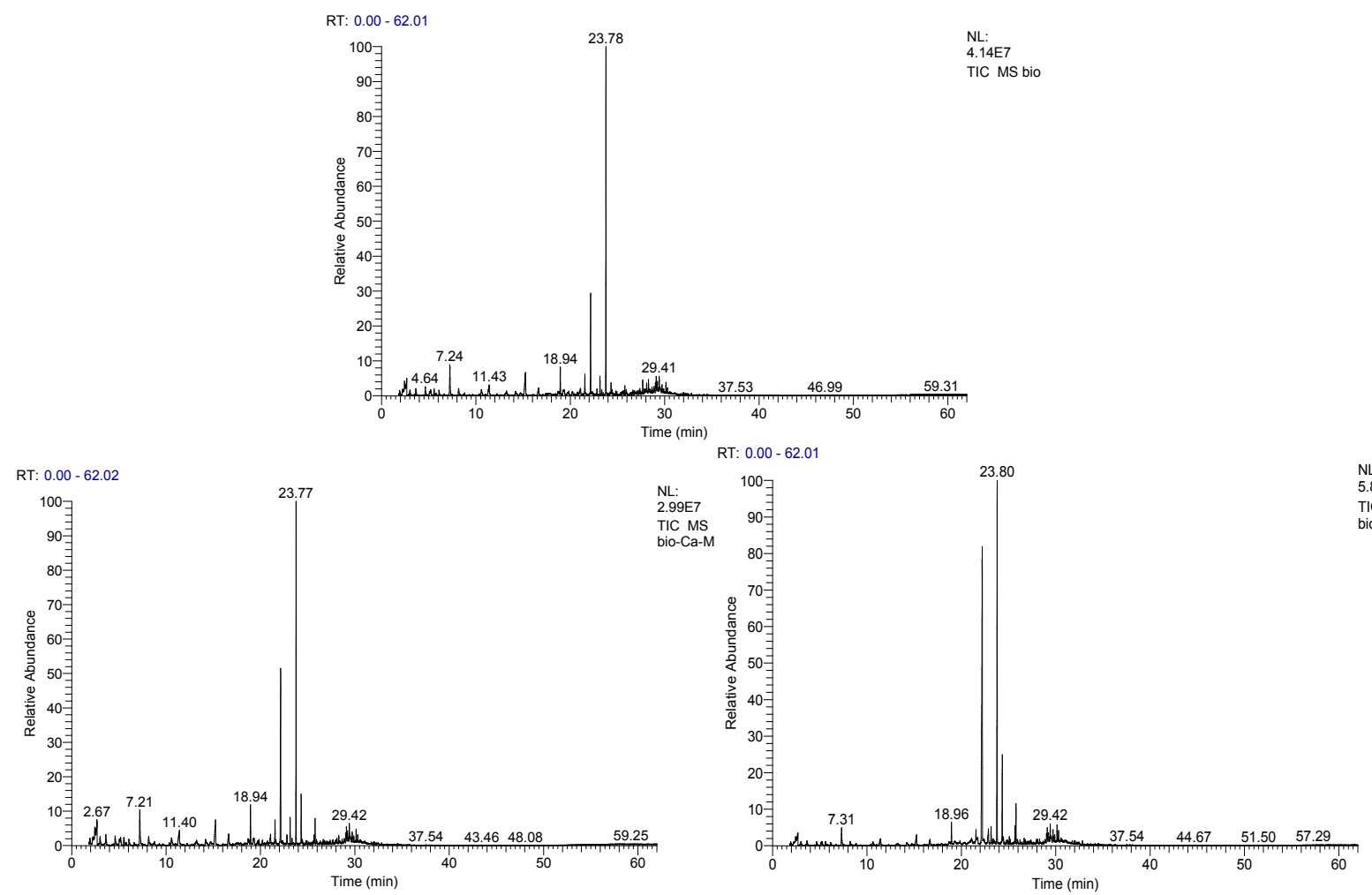

NL:
$5.89 \mathrm{E} 7$ TIC MS MS

Figure S2. Spectrums of response peak in each component during biomass catalytic pyrolysis by Py-GC-MS at $500{ }^{\circ} \mathrm{C}$
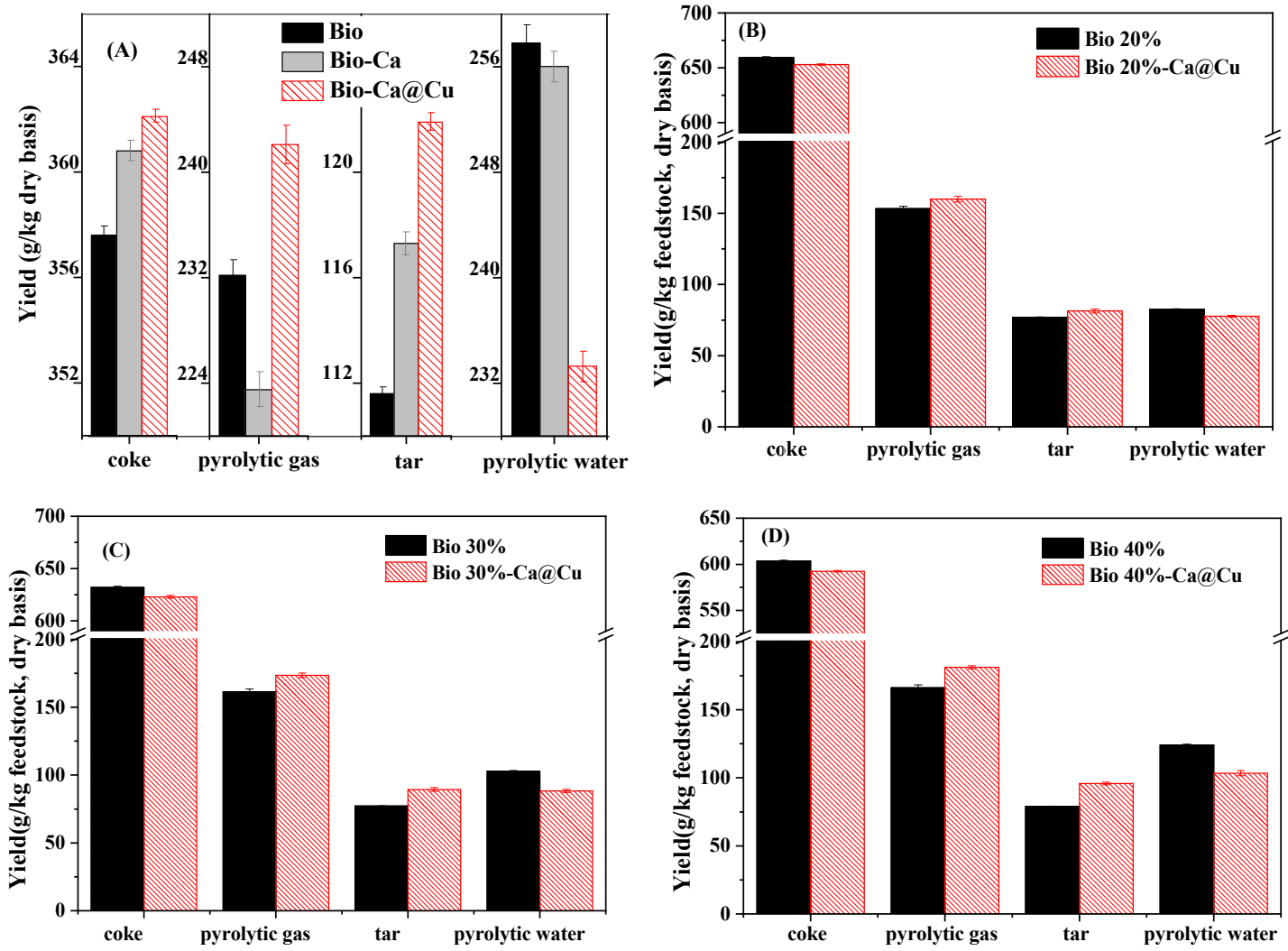

Figure S3. Distribution of pyrolytic products with/without catalysis during biomass pyrolysis intensification 

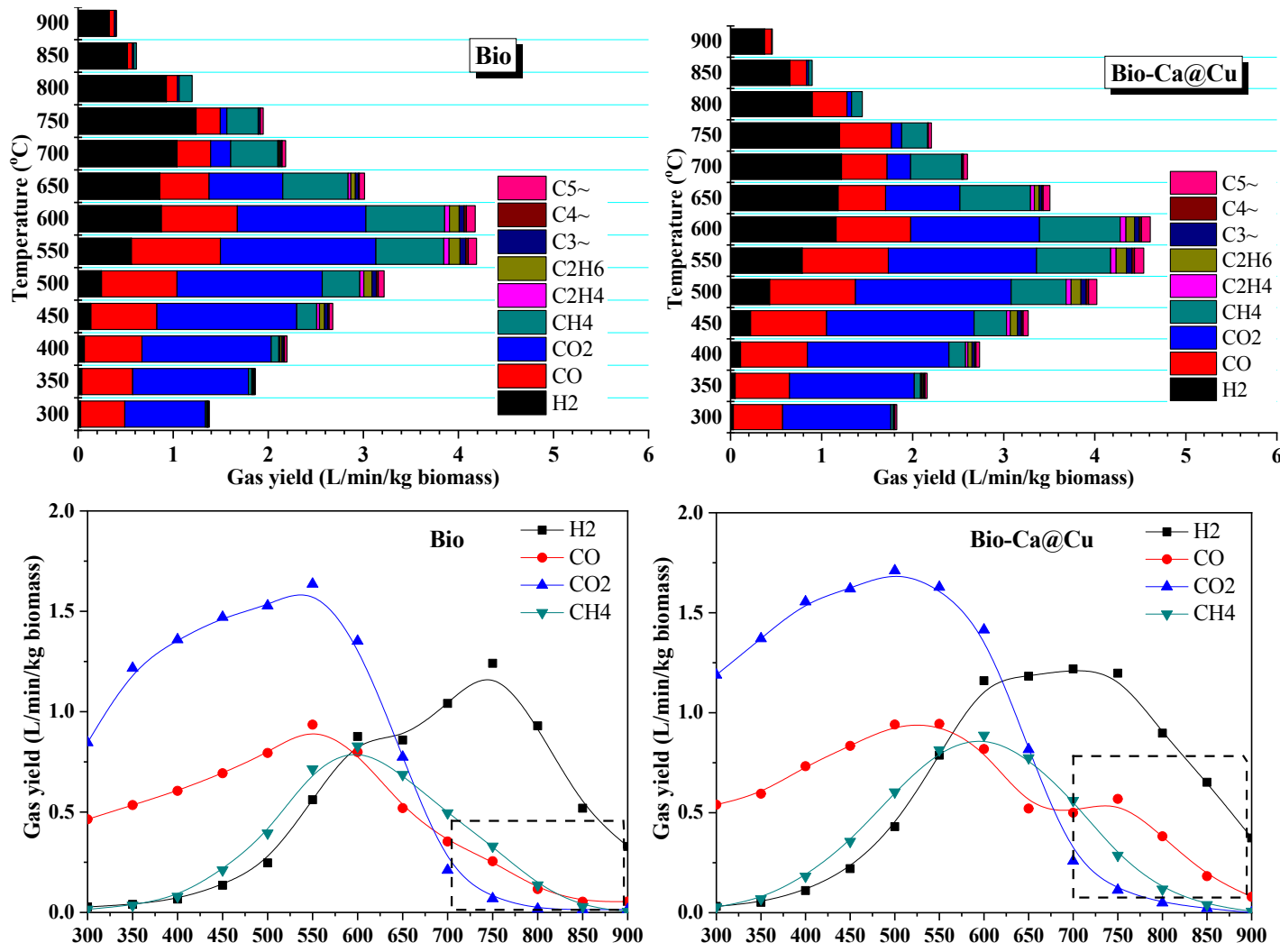
Temperature $\left({ }^{\circ} \mathrm{C}\right)$
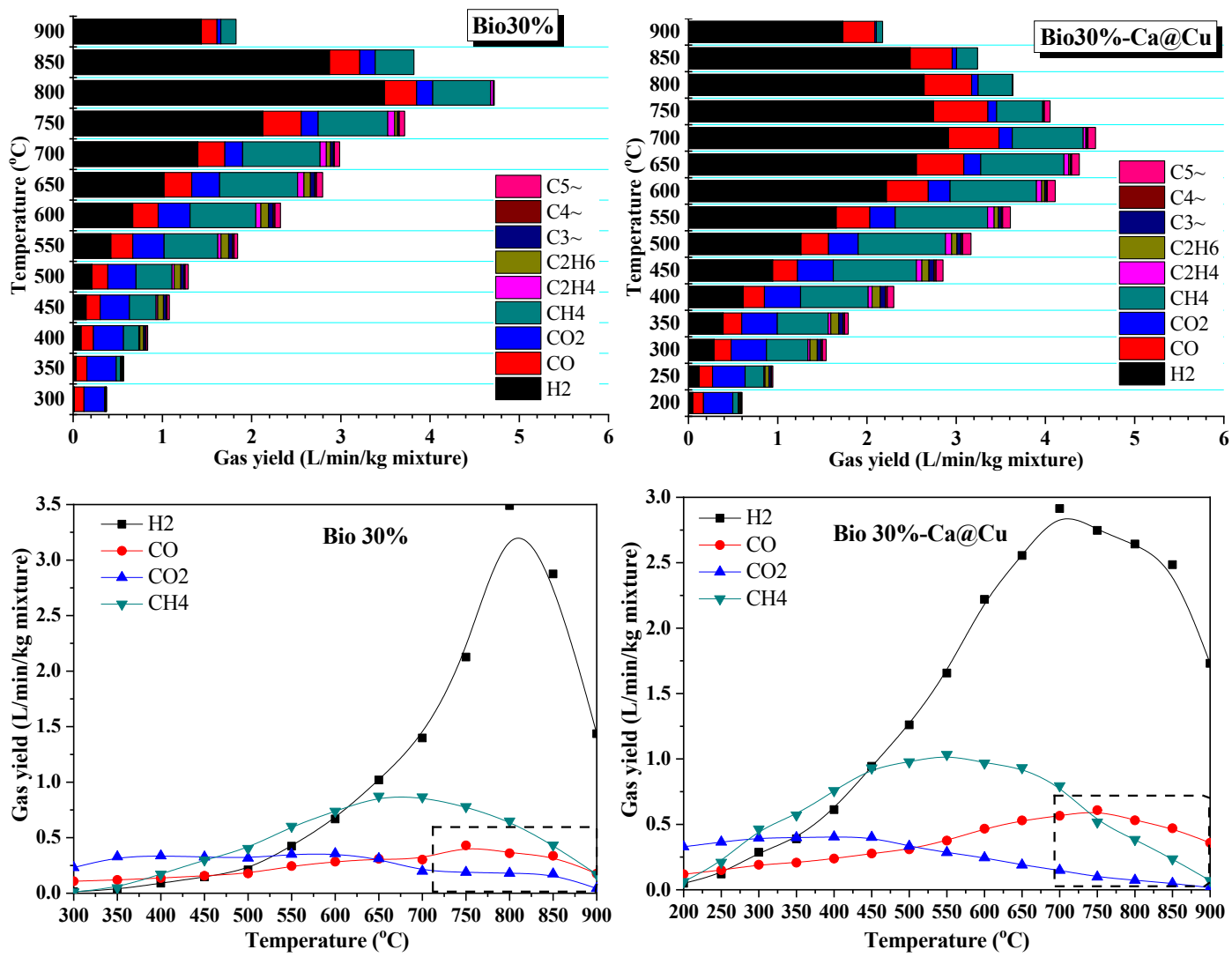

Figure S4. Distribution of gas component during biomass pyrolysis intensification with/without catalysis

Discussion for Figure S4: With the catalysis of $\mathrm{Ca} @ \mathrm{Cu}$, more $\mathrm{CO}$ were generated over 700 
${ }^{\circ} \mathrm{C}$, which was attributed to the selective fracture of the ether bond. Figure 4 shows that in the absence of catalysts, the bilateral fracture of oxygen-bridge (ether) bond releases $\mathrm{CO}$ and $\mathrm{CO} 2$ and decreases oxygen-containing groups in the heavy tar structure, thereby promoting the secondary-coke formation. In contrast, Figure 8 shows that the unilateral fracture of oxygenbridge (ether) bond during the catalysis retains the oxygen-containing groups on heavy tar structure which would hinder further growth of aromatic rings thereby reducing secondary-coke formation. 